\title{
Congenital Anomalies of the Kidney and Urinary Tract: A Genetic Disorder?
}

\author{
Ihor V. Yosypiv \\ Section of Pediatric Nephrology, Department of Pediatrics, Hypertension and Renal Center of Excellence, \\ Tulane University Health Sciences Center, New Orleans, LA 70112, USA \\ Correspondence should be addressed to Ihor V. Yosypiv, iiosipi@tulane.edu
}

Received 20 December 2011; Accepted 21 March 2012

Academic Editor: Paul Goodyer

Copyright ( $) 2012$ Ihor V. Yosypiv. This is an open access article distributed under the Creative Commons Attribution License, which permits unrestricted use, distribution, and reproduction in any medium, provided the original work is properly cited.

Congenital anomalies of the kidney and urinary tract (CAKUTs) occur in 3-6 per 1000 live births, account for the most cases of pediatric end-stage kidney disease (ESKD), and predispose an individual to hypertension and cardiovascular disease throughout life. Although CAKUTs are a part of many known syndromes, only few single-candidate causative genes have been implicated so far in nonsyndromic cases of human CAKUT. Evidence from mouse models supports the hypothesis that non-syndromic human CAKUT may be caused by single-gene defects. Because increasing numbers of children with CAKUT are surviving to adulthood, better understanding of the molecular pathogenesis of CAKUT, development of new strategies aiming at prevention of CAKUT, preservation of renal function, and avoidance of associated cardiovascular morbidity are needed. In this paper, we will focus on the knowledge derived from the study of syndromic and non-syndromic forms of CAKUT in humans and mouse mutants to discuss the role of genetic, epigenetic, and in utero environmental factors in the pathogenesis of non-syndromic forms of CAKUT in children with particular emphasis on the genetic contributions to CAKUT.

\section{Introduction}

Congenital anomalies of the kidney and urinary tract (CAKUTs) occur in 3-6 per 1000 live births and are responsible for $34-59 \%$ of chronic kidney disease (CKD) and for $31 \%$ of all cases of end-stage kidney disease (ESKD) in children in the United States (Table 1) [1-8]. All children with ESKD require renal replacement therapy and up to $70 \%$ of them develop hypertension [9]. Given that the survival rate of children with ESKD is about 30 times lower than that of healthy children [10], new strategies are needed to prevent CAKUT, preserve renal function, and reduce associated cardiovascular morbidity.

CAKUTs comprise a wide range of renal system structural and functional malformations that occur at the level of the kidney (e.g., hypoplasia and dysplasia), collecting system (e.g., hydronephrosis and megaureter), bladder (e.g., ureterocele and vesicoureteral reflux), or urethra (e.g., posterior urethral valves) [16]. With improved prenatal screening, many cases of CAKUT are diagnosed by antenatal ultrasonography performed on 18-20 weeks of gestation. Most common antenatal manifestations of CAKUT include oligohydramnios or variations in gross morphology of the kidney, ureter, or bladder. Postnatal manifestations of CAKUT may include presence of palpable abdominal mass or single umbilical artery, feeding difficulties, decreased urine output, deficient abdominal wall musculature, and undescended testes in a male infant or multiorgan birth defects [17]. Despite the broad spectrum, all forms of CAKUT result from faulty renal system development $[16,18,19]$. Although many forms of CAKUT occur in the context of multiorgan malformation syndrome (http://www.ncbi.nlm.nih.gov/omim), most cases of CAKUT are nonsyndromic [16]. Syndromic CAKUTs develop in association with additional congenital abnormalities outside of the kidney and urinary tract and manifest clinically recognizable features of a known syndrome, whereas in nonsyndromic CAKUT congenital structural anomalies are confined only to the kidney and urinary tract. Although only few single-candidate causative genes have been implicated so far in nonsyndromic cases of human CAKUT [20,21], evidence from mouse models supports the hypothesis that 
TABLE 1: Prevalence of CAKUT.

\begin{tabular}{lll}
\hline Type of malformation & Prevalence & References \\
\hline Unilateral renal agenesis & & \\
$\quad$ Fetuses & $0.008 \%$ & {$[8]$} \\
$\quad$ Newborns & & {$[11]$} \\
Bilateral renal agenesis & & {$[8]$} \\
$\quad$ Fetuses & $0.013 \%$ & {$[11]$} \\
Newborns & 1 in 30,000 & {$[12]$} \\
Congenital hydronephrosis & 1 in 1,000 live & \\
Renal hypodysplasia & births & {$[8]$} \\
Fetuses & & {$[8]$} \\
Newborns & $0.027 \%$ & {$[13]$} \\
Horseshoe kidney & 1 in 400 live births & \\
PUV & 1 in 1,000 & {$[8]$} \\
Fetuses & newborns & \\
VUR & & {$[14]$} \\
Infants with hydronephrosis on & $3-19 \%$ & \\
prenatal ultrasonography & & \\
Well children & $1-2 \%$ & \\
Children with UTI & $25-40 \%$ & \\
Unilateral duplex ureter & $1-8 \%$ & \\
\hline
\end{tabular}

nonsyndromic human CAKUT may be caused by single-gene defects.

\section{Evidence from Mouse Models to Suggest Monogenic Causes of CAKUT}

Genetic manipulations in mice identified a number of genes and gene networks that orchestrate normal development of the kidney and urinary tract (renal developmental genes $(\mathrm{RDGs})$ ) and provided new insights into the pathogenesis of CAKUT $([22,23]$, http://www.gudmap.org/). Because concerted inductive interactions of many RDGs expressed in the mesenchyme (anlagen of the nephron), stroma (anlagen of the renal interstitium), ureteric bud (UB, anlagen of the renal pelvis, calyces, ureter, and collecting ducts), and cloaca (anlagen of the bladder and urethra) at multiple developmental stages are required for normal morphogenesis of the kidney and lower urinary tract [22], single-RDG mutations might affect kidney development at multiple steps and cause a broad phenotypic spectrum of CAKUT that ranges from vesicoureteral reflux (VUR) to renal agenesis [16]. For example, mice with global genetic deletion of Ret, a receptor tyrosine (Tyr) kinase (RTK) for glial-derived neurotrophic factor (GDNF) produced in the mesenchyme, expressed in the UB exhibit a spectrum of anomalies ranging in severity from unior bilateral renal and ureteral agenesis, to blind-ending ureters with no kidney tissue, to hypoplastic/dysplastic kidney rudiments [24]. Moreover, specific CAKUT phenotype in Ret mutants depends on distinct Ret-stimulated signaling pathways. ${ }^{T y r 1062}$ Ret mouse mutants, characterized by aberrant phosphatidylinositol 3-kinase (PI3K)/Akt and rat sarcoma (Ras)/extracellular-signal-regulated kinase (Erk) 1/2 signaling, exhibit more severe defects, which include renal agenesis, hypodysplasia, and ureteral defects, whereas ${ }^{T y r} 1015$ Ret mutans, characterized by aberrant phospholipase C (PLC) $\gamma$ signaling, manifest renal hypodysplasia and ureteral defects, but not renal agenesis [25]. The diverse phenotypes of these Ret mutants resemble human CAKUT, including incomplete penetrance (lack of disease manifestation in the presence of gene mutation) and variable expressivity (variation in type and severity of disease between individuals with the same gene mutation). Despite new insights into the molecular basis of CAKUT obtained in model organisms, integrated understanding of the role of genetic factors in the pathogenesis of nonsyndromic forms of CAKUT in humans is far from complete.

\section{What Is the Evidence That Nonsyndromic Human CAKUTs Have a Genetic Basis?}

The possibility of genetic basis of nonsyndromic CAKUT is supported by occurrence of familial cases of nonsyndromic renal agenesis, hypodysplasia, renal tubular dysgenesis, multicystic dysplastic kidney (MCDK), or VUR [26-30]. The observations that diverse forms of CAKUT occur in the same family [31] suggest that specific genetic mutations can potentially lead to CAKUT, but the final renal system phenotype depends on either genetic background or environmental factors. Despite recent identification of mutations in a number of genes in patients with nonsyndromic forms of CAKUT (Table 2), evidence to suggest that all cases of nonsyndromic CAKUT in humans are due to single-gene mutations is missing. Most studies report presence of known potential CAKUT-causing RDG mutations only in minority (1.9-20\%) of patients with nonsyndromic CAKUT. Mutations in HNF1 $\beta$, Pax2, UMOD, or Eya1 are detected in $1.9 \%$ of 538 patients from 456 families of predominantly European population with nonsyndromic CAKUT [32]. Mutations in hepatocyte nuclear factor- $1 \beta$ (HNF1 $\beta)$ are identified in $10 \%$ of Japanese children with renal hypodysplasia and unilateral MCDK [33]. Mutations in HNF1 $\beta$, Eya1, Six1, Sall1 and Pax2 are identified in $5-15 \%$ of children from European population with nonsyndromic CAKUT [20]. Massively parallel exon sequencing of 30 candidate genes in pooled DNA from children with unilateral renal agenesis, renal hypodysplasia, or VUR in the United States identified novel mutations in 4 genes (Ret, BMP4, FRAS1, and FREM2) in 17\% of cases [21]. Pax-2, but not its downstream target gene, GDNF, polymorphism (a variation in the DNA sequence at a given locus that is too common to be due merely to new mutation) is associated with reduced kidney size in neonates $[34,35]$. The differential effects of $\operatorname{Pax} 2$ and GDNF polymorphism on CAKUT phenotype may be due, in part, to unidentified cellspecific cofactors that regulate gene expression. Of interest, polymorphism in GDNF receptor Ret is associated with reduced kidney size in neonates [36]. These findings may be interpreted to suggest that while RTKs other than Ret are unable to rescue renal phenotype in the absence of Ret, growth factors other than GDNF can act via Ret to do so. 


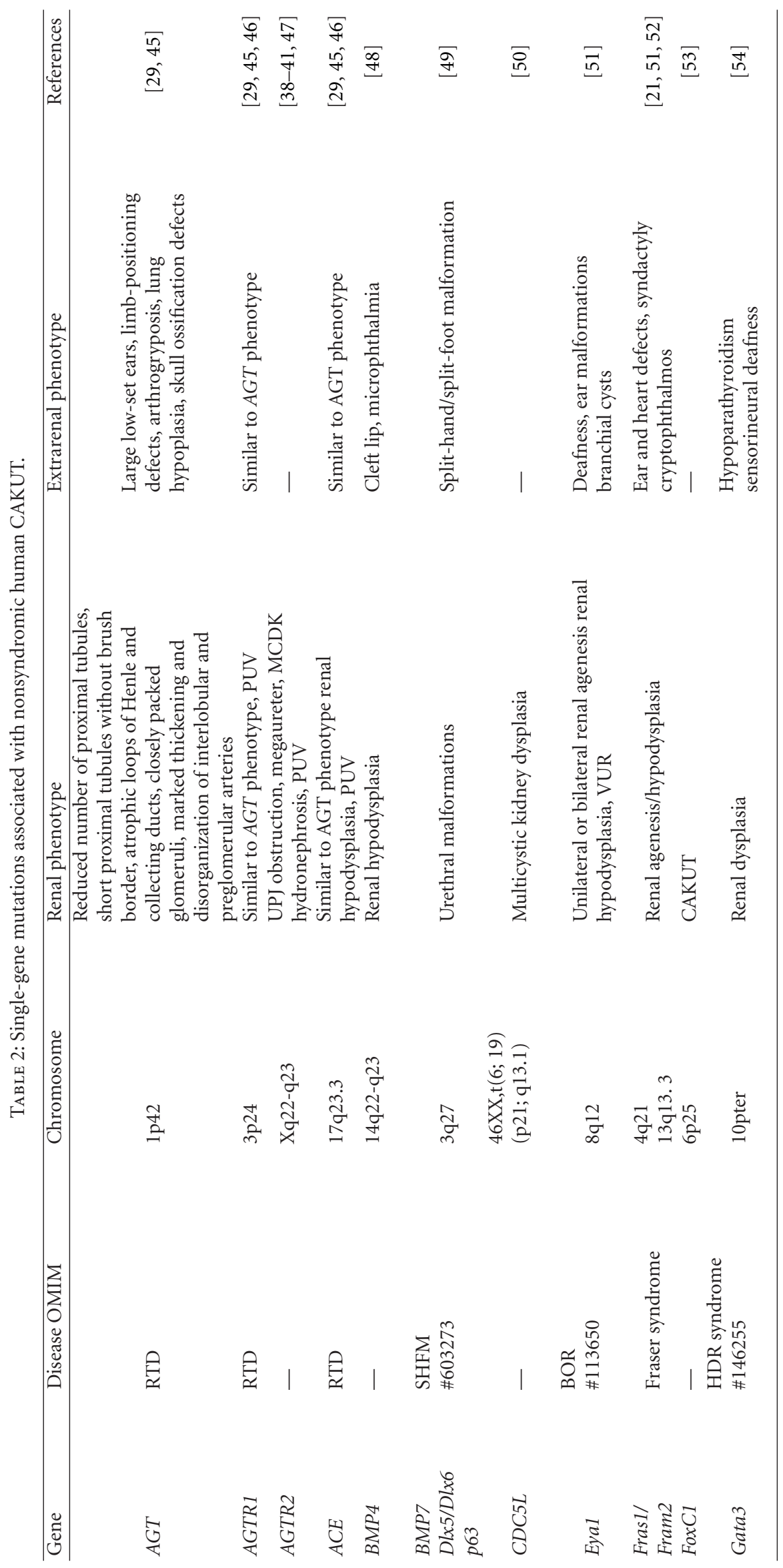




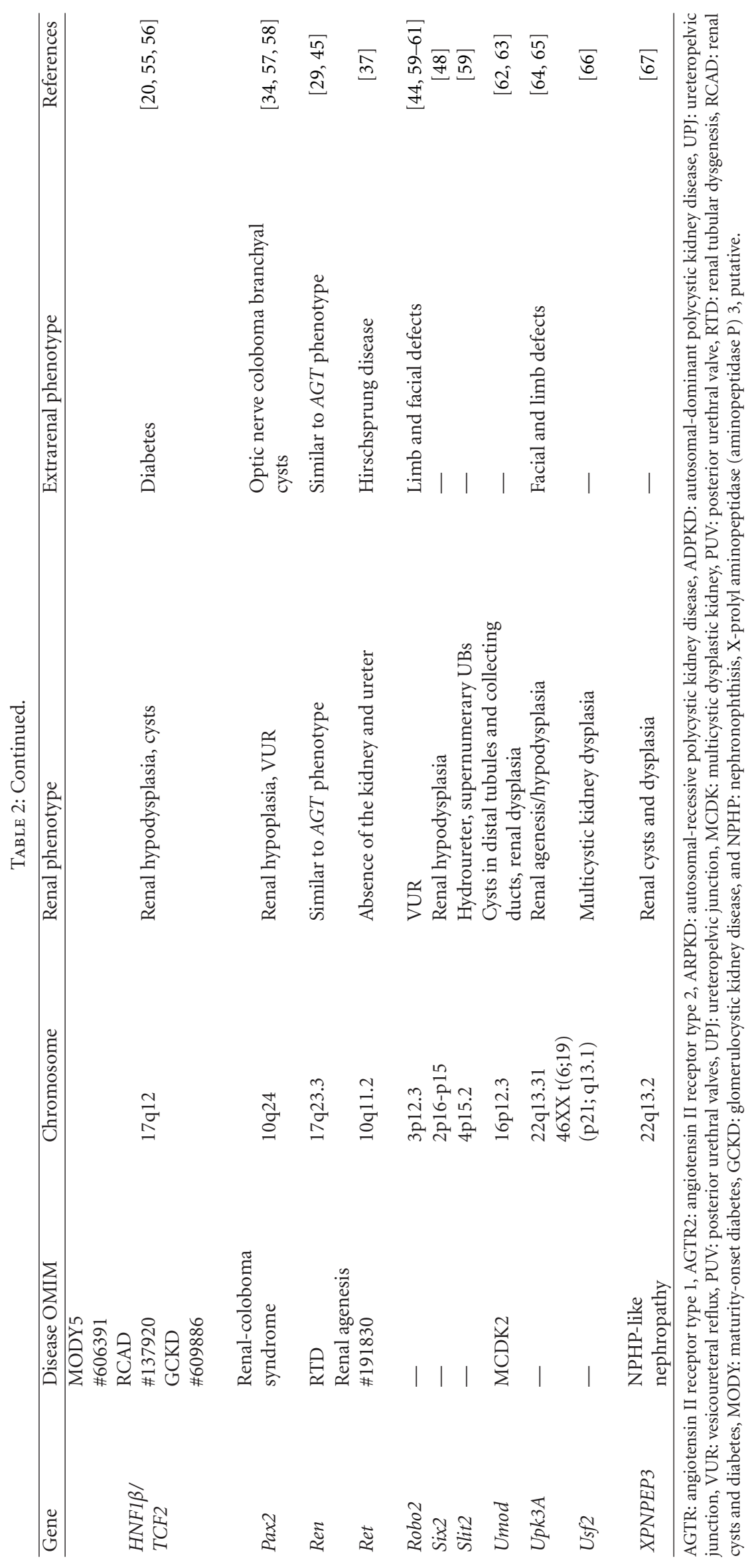


Notably, mutations in Ret are found in 35\% of humans with various forms of renal agenesis [37]. Association of single polymorphism in the human $A T_{2} R$ gene, 1332A > G transition, with CAKUT has been reported in children with ureteropelvic junction (UPJ) stenosis, megaureter, MCDK, renal agenesis, and hydronephrosis from Germany, Italy, Korea, and the United States [38-41]. In contrast, several studies were unable to detect any known mutations in several RDGs linked to CAKUT in mice in humans. No known $U M O D$ (European population) or $A T_{2} R$ (Japanese population) gene mutations were identified in children with diverse forms of nonsyndromic CAKUT [42, 43]. There was no association of primary VUR with mutations in Pax2, HNF1 $\beta$, Ret, or Robo2 in children from European population [44]. Thus, the contribution of genetic mutations to the cause of nonsyndromic CAKUT in the majority of children remains unresolved.

Several studies report a discrepancy in the impact of genetic mutations on CAKUT phenotype between mice and humans. For example, despite severe renal phenotype observed in Robo2/Slit2-mutant mice, which includes formation of supernumerary ureters [59], these gene mutations are very rarely associated with familial nonsyndromic VUR in children [60]. Mutations in the genes encoding for angiotensinogen (AGT), renin, ACE, or angiotensin II receptor type 1 (AGTR1) in mice result in severe medullary hypoplasia and hydronephrosis [68], a phenotype not observed in humans with $A G T$, renin, $A C E$, or AGTR1 mutations [29]. The reasons for different CAKUT phenotypes observed in mice and humans with mutations in the same RDG may include severity of mutation (e.g., loss-of function mutation in mice models and missense mutations in humans), a higher complexity of epistatic or epigenetic interactions in humans compared to mice, or other factors. Importantly, the discrepancy between the mice and human CAKUT phenotype calls for caution when extrapolating findings observed in mice to humans.

\section{Mechanisms That Dictate the Phenotypic Spectrum of CAKUT}

Phenotypic heterogeneity of CAKUT can result from the following mechanisms: mutations in a single or multiple genes linked to human CAKUT [16], genetic [69-74] or epigenetic modifiers [75], mode of inheritance and environment [76].

\subsection{Mutations in a Single or Multiple Genes Linked to Human CAKUT}

4.1.1. Locus Heterogeneity. Although such hereditary cystic kidney diseases as ADPKD and nephronophthisis are not a part of CAKUT phenotype spectrum and should not be confused with CAKUT, important lessons can be drawn from our current knowledge of these and other forms of hereditary renal disease. In this regard, genetic locus heterogeneity (mutations in genes at different chromosomal loci) is a major determinant of interfamilial disease variability in ADPKD, accounting for earlier onset of ESKD in patients with ADPKD1 compared with patients with ADPKD2 [77] and of disease severity in children with nephronophthisis-related ciliopathies [78]. Whether genetic locus heterogeneity plays a role in interfamilial variability in CAKUT remains to be determined.

4.1.2. Allelic Heterogeneity. The specific combination of mutations dictates phenotypic outcome in some forms of CAKUT. For example, the presence of two truncating mutations in PKHD1 results in nonfunctional fibrocystin and leads to death in the neonatal period $[77,79]$. In contrast, patients with two missense (hypomorphic alleles that produce partially functional fibrocystin) mutations or a missense and a truncating mutation have a more favorable prognosis. Histologically, the severity of collecting duct dilatation and of degenerative changes in cortical tubules is more pronounced in neonates with truncating than missense PKHD1 mutations [79]. Unlike in ARPKD, no clear correlation between mutation type and the severity of kidney disease is detected in ADPKD1 or $2[77,80]$. Considerable disease variability in patients with the same PKD1 or PKD2 mutations supports the notion that additional genetic and environmental factors may modulate phenotypic outcome in ADPKD. Given that two null mutations in only NPHP6, but not in NPHP2-NPHP5, caused a more severe renal phenotype compared to null/missense mutations, the authors proposed that genetic locus heterogeneity is the major determinant of the disease phenotype with allelic heterogeneity being important only for certain genes [78].

4.1.3. Allelic Variation. Allelic variation in gene expression (significant difference in gene expression between the two alleles, which is transmitted by Mendelian inheritance) is common in the human genome [81]. Thus, allelic variation may modulate the level of various CAKUT mutants, leading to broad phenotypic spectrum of CAKUT.

4.2. Genetic Modifiers. Modifier genes can potentially modulate the CAKUT phenotype despite a unique CAKUT genotype. In this case, mutation in one gene will cause CAKUT or alter the phenotype only in the presence of genetic change in another gene (epistatic gene interactions). One of the wellrecognized examples involves worsening the severity of ADPKD in contiguous deletions of PKD1 and adjacent tuberous sclerosis gene, Tsc2 [82]. Interactions between mouse orthologs of the genes linked to human CAKUT such as $P K H D 1$ and $H N F 1 \beta, P K D 1$ and $P K D 2$ or polycystin 1 , the product of the PKD1 gene and tuberin, the product of the Tsc2 gene have been reported in animal models [72-74, 83]. Large intrafamilial variability in renal disease progression in siblings with ADPKD, coupled with a significant excess of variability in siblings compared with monozygotic twins, provides further support for a role of genetic modifiers in children with ADPKD [84]. The fact that the spectrum of CAKUT phenotypes associated with $H N F 1 \beta$ or uromodulin $(U M O D)$ mutations and age of their manifestations differ $[33,55,85,86]$ may be due, in part, to the ability of $H N F 1 \beta, a$ developmentally regulated transcription factor, to regulate expression of $U M O D$ or aggravate the phenotype of 
ADPKD [87, 88]. Available evidence suggests that epistatic gene interactions may be important in the pathogenesis of nephronophthisis. For example, NPHP1 mutation causes nephronophthisis, whereas NPHP6 mutation alone does not lead to disease. In contrast, a combination of the same mutations in NPHP1 and NPHP6 causes an additional extrarenal disease phenotype [89]. Other RDGs that interact genetically and may influence renal phenotype include Pax 2 and $L M X 1 B$ or Six1 and Tbx18 $[69,70]$.

4.3. Epigenetic Modifiers. Great importance has been recently attributed to the epigenetic regulation of gene expression (epigenetic programming) and disease causality. The major mechanisms in epigenetic control of gene regulation are DNA or chromatin protein methylation and acetylation. Chromatin methylation and acetylation recruit additional proteins that can modify histones to form compact, inactive (heterochromatin), or opened, active (euchromatin), chromatin and alter RDG transcription $[90,91]$. Specific combinations of these epigenetic marks determine whether to maintain a given RDG in an uncommitted transcriptional state with its transcripts present at low levels (poised state), stimulate its transcription by making it accessible to the transcription machinery, or silence it by packing into heterochromatin inaccessible to the transcription machinery [92]. Recent studies demonstrate that Pax2, a transcription factor critical for normal kidney development, is an important determinant of epigenetic marks during metanephric organogenesis [75]. Treatment of embryonic kidneys with inhibitors of histone deacetylases (HDACs), an evolutionary conserved group of enzymes that remove acetyl groups from histone tails, impairs UB branching and causes growth arrest and apoptosis [93]. Moreover, epigenetic programming may be inherited and may be involved in predisposition to complex diseases [94].

4.4. Mode of Inheritance. The mode of inheritance dictates the degree of genetic causality. In monogenic (Mendelian) recessive diseases, mutation in a given gene conveys a high risk of developing the disease by a defined age in early childhood. For example, in ARPKD disease-causing mutation conveys almost 100\% risk of developing the disease $[77,79]$. These diseases usually manifest complete penetrance (all individuals who have the disease-causing mutation have clinical symptoms of the disease) and present earlier in life. The strength of genotype-phenotype correlation is reduced in autosomal dominant, compared with recessive, diseases [77]. This may be due to incomplete penetrance or variable expression. This is also true for nonsyndromic forms of CAKUT such as unilateral and bilateral renal agenesis or severe dysplasia, most of which manifest autosomal dominant trait with penetrance between 50 and $90 \%$ and variable expression [95]. Genotype-phenotype correlations are the weakest in polygenic (complex) diseases, where mutations in multiple genes act in concert with environmental effects to cause a phenotype later in life. Although polygenic causation cannot be excluded in congenital solitary kidney, it is less likely since risks to offsprings are higher than expected for a strict

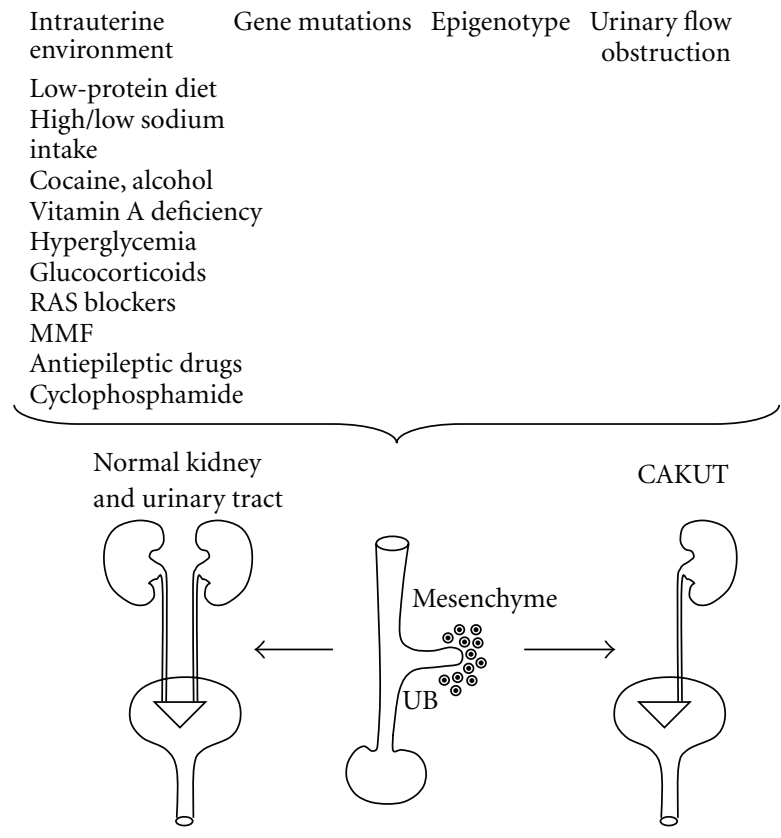

FIGURE 1: Schematic representation of the proposed impact of intrauterine environment, gene mutations, epigenotype, and urinary flow obstruction on the pathogenesis of CAKUT. These factors cause aberrant interactions among the mesenchyme, ureteric bud (UB), or bladder anlagen to result in CAKUT [102]. Please see text for details.

multifactorial condition [30]. On the other hand, mutations in RDGs such as Six2 and Bmp4 are identified only in 3\% of children from European population with nonsyndromic CAKUT that include unilateral renal agenesis and renal hypodysplasia [48]. High variability and low penetrance of Six 2 and Bmp4 mutations observed in this study are in accordance with the presumed polygenic inheritance of CAKUT. Unfortunately, such terms as "incomplete penetrance" or "variable expression" do not explain a biological mechanism but rather are labels for our ignorance.

4.5. Environment. Intrauterine environment has been linked to CAKUT. Maternal low-protein diet initiated at onset of pregnancy in mice alters expression of RDGs in the embryonic metanephros and reduces nephron number [76]. One mechanism by which maternal low-protein diet may cause renal hypoplasia is by increasing concentration of glucocorticoids via downregulation of placental steroid-metabolizing enzyme $11 \beta$-hydroxysteroid dehydrogenase type 2 [96]. Another mechanism may involve downregulation of angiotensin II contents in the embryonic kidney [97]. Both excessively high and low maternal sodium intake during pregnancy in the rat cause aberrant expression of critical RDGs and reduce the final number of glomeruli in the offspring, predisposing to hypertension later in life [98]. Additional factors that have been shown to result in CAKUT in children include maternal use of cocaine or alcohol during gestation (Figure 1) [99, 100]. Occurrence of renal hypodysplasia caused by high maternal salt intake during gestation 
in bradykinin $B 2$ receptor-deficient mice provides proof of the principle that environmental factors may act in concert with single-gene mutations to cause CAKUT [101]. The mechanistic basis for CAKUT associated with altered intrauterine environment remains to be elucidated further.

\section{Diagnostic Genomics Technologies in CAKUT}

Three novel techniques are now available to accelerate discovery of causative genes in nonsyndromic CAKUT: genome-wide association studies (GWASs), exome capture, and next-generation DNA sequencing. GWASs avoid candidate-gene approach and map whole genomic DNA with markers to find loci (most commonly by genotyping singlenucleotide polymorphisms (SNPs)) associated with or in linkage disequilibrium (occurrence of some combinations of alleles or genetic markers in a population more often or less often than would be expected from a random formation of haplotypes from alleles based on their frequencies) with CAKUT. Although the ability of GWASs to identify the impact of common and rare variants on nonsyndromic CAKUT remains to be determined, GWASs generally rarely succeed in securely implicating specific genes in specific polygenic (common) diseases [103]. Exome capture and nextgeneration sequencing represent the most comprehensive study of the role of genetic variations in disease. Exome represents protein-coding subset of a genome. Because exons harbor $85 \%$ of mutations in single-gene diseases [104], exome capture (DNA hybridization with human exome array followed by amplification of captured DNA fragments) with consecutive next-generation sequencing (massively parallelized sequencing of captured and amplified DNA fragments) will help to identify CAKUT-causing alleles [105]. Although these techniques exemplify a fundamental advance for nephrology research, they are costly and require specific bioinformatic software for stringent data analysis, interpretation and reporting, and a large number of patients to yield adequate statistical power.

\section{Implications of the State of Current Knowledge Regarding Genetic Cause of CAKUT}

The cause of most cases of nonsyndromic CAKUT remains unknown. These types of CAKUT are assumed to be multifactorial and occur as a result of combination of epigenetic and environmental factors affecting genetically susceptible individuals. It is conceivable that polymorphism in a single given RDG may be in linkage disequilibrium with a separate, causative, mutation in a nearby gene. Perhaps polymorphisms or mutations in other genes must coexist to result in CAKUT. Application of GWASs, exome (and subsequently whole genome) capture and next-generation sequencing studies using the proper curation of CAKUT phenotypes, a family-based research design and properly-powered patient sample size will assist in identification of specific genetic determinants underlying nonsyndromic CAKUT and assess their causality. Establishment of collaborative framework among multiple centers throughout the world is required to unravel the genetic basis of CAKUT and provide precise genetic counseling for CAKUT patients and their relatives to enable personalized medical care based on the detailed understanding of the molecular pathogenesis of the disease.

\section{References}

[1] A. Daneman and D. J. Alton, "Radiographic manifestations of renal anomalies," Radiologic Clinics of North America, vol. 29, no. 2, pp. 351-363, 1991.

[2] K. Nakanishi and N. Yoshikawa, "Genetic disorders of human congenital anomalies of the kidney and urinary tract (CAKUT)," Pediatrics International, vol. 45, no. 5, pp. 610 616, 2003.

[3] North American Pediatric Renal Trials and Collaborative Studies, NAPRTCS Annual report, 2010 https://web.emmes .com/study/ped/annlrept/2010_Report.pdf.

[4] "ESPN/ERA-EDTA Registry UK Renal Registry," annual report, 2008, http://www.espn-reg.org/.

[5] G. Ardissino, V. Daccò, S. Testa et al., "Epidemiology of chronic renal failure in children: data from the ItalKid project," Pediatrics, vol. 111, no. 4, part 1, pp. e382-e387, 2003.

[6] M. A. Lewis, J. Shaw, M. Sinha, S. Adalat, F. Hussain, and C. Inward, "UK renal registry 11 th annual report (December 2008): chapter 13 demography of the UK paediatric renal replacement therapy population," Nephron Clinical Practice, vol. 111, no. 1, pp. c257-c267, 2009.

[7] S. Hattori, K. Yosioka, M. Honda, and H. Ito, "The 1998 report of Japanese National Registry data on pediatric endstage renal disease patients," Pediatric Nephrology, vol. 17, no. 6, pp. 456-461, 2002.

[8] A. Wiesel, A. Queisser-Luft, M. Clementi et al., "Prenatal detection of congenital renal malformations by fetal ultrasonographic examination: an analysis of 709,030 births in 12 European countries," European Journal of Medical Genetics, vol. 48, no. 2, pp. 131-144, 2005.

[9] H. J. Baluarte, A. B. Gruskin, J. R. Ingelfinger, D. Stablein, and A. Tejani, "Analysis of hypertension in children post renal transplantation-a report of the North American Pediatric Renal Transplant Cooperative Study (NAPRTCS)," Pediatric Nephrology, vol. 8, no. 5, pp. 570-573, 1994.

[10] J. W. Groothoff, M. P. Gruppen, M. Offringa et al., "Mortality and causes of death of end-stage renal disease in children: a Dutch cohort study," Kidney International, vol. 61, no. 2, pp. 621-629, 2002.

[11] M. Hiraoka, C. Hori, H. Tsukahara, K. Kasuga, Y. Ishihara, and M. Sudo, "Congenitally small kidneys with reflux as a common cause of nephropathy in boys," Kidney International, vol. 52, no. 3, pp. 811-816, 1997.

[12] E. Garne, M. Loane, D. Wellesley, I. Barisic, and EUROCAT Working Group, "Congenital hydronephrosis: prenatal diagnosis and epidemiology in Europe," Journal of Pediatric Urology, vol. 5, no. 1, pp. 47-52, 2009.

[13] A. Z. Weizer, A. D. Silverstein, B. K. Auge et al., "Determining the incidence of horseshoe kidney from radiographic data at a single institution," Journal of Urology, vol. 170, no. 5, pp. 1722-1726, 2003.

[14] G. Williams, J. T. Fletcher, S. I. Alexander, and J. C. Craig, "Vesicoureteral reflux," Journal of the American Society of Nephrology, vol. 19, no. 5, pp. 847-862, 2008. 
[15] S. K. Chowdhary, A. Lander, K. Parashar, and J. J. Corkery, "Single-system ectopic ureter: a 15-year review," Pediatric Surgery International, vol. 17, no. 8, pp. 638-641, 2001.

[16] R. Song and I. V. Yosypiv, "Genetics of congenital anomalies of the kidney and urinary tract," Pediatric Nephrology, vol. 26, no. 3, pp. 353-364, 2011.

[17] H. Nakai, H. Asanuma, S. Shishido, S. Kitahara, and K. Yasuda, "Changing concepts in urological management of the congenital anomalies of kidney and urinary tract, CAKUT," Pediatrics International, vol. 45, no. 5, pp. 634-641, 2003.

[18] A. Schedl, "Renal abnormalities and their developmental origin," Nature Reviews Genetics, vol. 8, no. 10, pp. 791-802, 2007.

[19] J. E. Cain, V. Di Giovanni, J. Smeeton, and N. D. Rosenblum, "Genetics of renal hypoplasia: insights into the mechanisms controlling nephron endowment," Pediatric Research, vol. 68, no. 2, pp. 91-98, 2010.

[20] S. Weber, V. Moriniere, T. Knüppel et al., "Prevalence of mutations in renal developmental genes in children with renal hypodysplasia: results of the ESCAPE study," Journal of the American Society of Nephrology, vol. 17, no. 10, pp. 28642870, 2006.

[21] P. Saisawat, V. Tasic, V. Vega-Warner et al., "Identification of two novel CAKUT-causing genes by massively parallel exon resequencing of candidate genes in patients with unilateral renal agenesis," Kidney International, vol. 81, pp. 196-200, 2012.

[22] F. Costantini and R. Kopan, "Patterning a complex organ: branching morphogenesis and nephron segmentation in kidney development," Developmental Cell, vol. 18, no. 5, pp. 698-712, 2010.

[23] C. Mendelsohn, "Using mouse models to understand normal and abnormal urogenital tract development," Organogenesis, vol. 5, no. 1, pp. 306-314, 2009.

[24] A. Schuchardt, V. D’Agati, L. Larsson-Blornberg, F. Costantini, and V. Pachnis, "Defects in the kidney and enteric nervous system of mice lacking the tyrosine kinase receptor Ret," Nature, vol. 367, no. 6461, pp. 380-384, 1994.

[25] S. Jain, A. Knoten, M. Hoshi et al., "Organotypic specificity of key RET adaptor-docking sites in the pathogenesis of neurocristopathies and renal malformations in mice," Journal of Clinical Investigation, vol. 120, no. 3, pp. 778-790, 2010.

[26] S. Arfeen, D. Rosborough, A. M. Luger, and K. D. Nolph, "Familial unilateral renal agenesis and focal and segmental glomerulosclerosis," American Journal of Kidney Diseases, vol. 21, no. 6, pp. 663-668, 1993.

[27] B. Murugasu, B. R. Cole, E. P. Hawkins, S. H. Blanton, S. B. Conley, and R. J. Portman, "Familial renal adysplasia," American Journal of Kidney Diseases, vol. 18, no. 4, pp. 490494, 1991.

[28] M. R. Eccles, R. R. Bailey, G. D. Abbott, and M. J. Sullivan, "Unravelling the genetics of vesicoureteric reflux: a common familial disorder," Human Molecular Genetics, vol. 5, pp. 1425-1429, 1996.

[29] O. Gribouval, M. Gonzales, T. Neuhaus et al., "Mutations in genes in the renin-angiotensin system are associated with autosomal recessive renal tubular dysgenesis," Nature Genetics, vol. 37, no. 9, pp. 964-968, 2005.

[30] E. McPherson, "Renal anomalies in families of individuals with congenital solitary kidney," Genetics in Medicine, vol. 9, no. 5, pp. 298-302, 2007.

[31] M. Kobayashi, B. S. Kaplan, R. D. Bellah et al., "Infundibulopelvic stenosis, multicystic kidney, and calyectasis in a kindred: clinical observations and genetic analysis," American Journal of Medical Genetics, vol. 59, no. 2, pp. 218-224, 1995.

[32] B. E. Hoskins, C. H. Cramer II, V. Tasic et al., "Missense mutations in EYA1 and TCF2 are a rare cause of urinary tract malformations," Nephrology Dialysis Transplantation, vol. 23, no. 2, pp. 777-779, 2008.

[33] M. Nakayama, K. Nozu, Y. Goto et al., "HNF1B alterations associated with congenital anomalies of the kidney and urinary tract," Pediatric Nephrology, vol. 25, no. 6, pp. 10731079, 2010.

[34] J. Quinlan, M. Lemire, T. Hudson et al., "A common variant of the PAX2 gene is associated with reduced newborn kidney size," Journal of the American Society of Nephrology, vol. 18, no. 6, pp. 1915-1921, 2007.

[35] Z. Zhang, J. Quinlan, D. Grote et al., "Common variants of the glial cell-derived neurotrophic factor gene do not influence kidney size of the healthy newborn," Pediatric Nephro$\log y$, vol. 24, no. 6, pp. 1151-1157, 2009.

[36] Z. Zhang, J. Quinlan, W. Hoy et al., "A common RET variant is associated with reduced newborn kidney size and function," Journal of the American Society of Nephrology, vol. 19, no. 10, pp. 2027-2034, 2008.

[37] M. A. Skinner, S. D. Safford, J. G. Reeves, M. E. Jackson, and A. J. Freemerman, "Renal aplasia in humans is associated with RET mutations," The American Journal of Human Genetics, vol. 82, no. 2, pp. 344-351, 2008.

[38] H. Nishimura, E. Yerkes, K. Hohenfellner et al., "Role of the angiotensin type 2 receptor gene in congenital anomalies of the kidney and urinary tract, CAKUT, of mice and men," Molecular Cell, vol. 3, no. 1, pp. 1-10, 1999.

[39] K. Hohenfellner, T. E. Hunley, C. Schloemer et al., "Angiotensin type 2 receptor is important in the normal development of the ureter," Pediatric Nephrology, vol. 13, no. 3, pp. 187-191, 1999.

[40] H. Hahn, S. E. Ku, K. S. Kim, Y. S. Park, C. H. Yoon, and H. I. Cheong, "Implication of genetic variations in congenital obstructive nephropathy," Pediatric Nephrology, vol. 20, no. 11, pp. 1541-1544, 2005.

[41] L. Rigoli, R. Chimenz, C. di Bella et al., "Angiotensinconverting enzyme and angiotensin type 2 receptor gene genotype distributions in Italian children with congenital uropathies," Pediatric Research, vol. 56, no. 6, pp. 988-993, 2004.

[42] M. Hiraoka, T. Taniguchi, H. Nakai et al., "No evidence for AT2R gene derangement in human urinary tract anomalies," Kidney International, vol. 59, no. 4, pp. 1244-1249, 2001.

[43] M. T. F. Wolf, B. E. Hoskins, B. B. Beck et al., "Mutation analysis of the Uromodulin gene in 96 individuals with urinary tract anomalies (CAKUT)," Pediatric Nephrology, vol. 24, no. 1, pp. 55-60, 2009.

[44] H. J. Cordell, R. Darlay, P. Charoen et al., "Whole-genome linkage and association scan in primary, nonsyndromic vesicoureteric reflux," Journal of the American Society of Nephrology, vol. 21, no. 1, pp. 113-123, 2010.

[45] M. Lacoste, Y. Cai, L. Guicharnaud et al., "Renal tubular dysgenesis, a not uncommon autosomal recessive disorder leading to oligohydramnios: role of the renin-angiotensin system," Journal of the American Society of Nephrology, vol. 17, no. 8, pp. 2253-2263, 2006.

[46] L. Peruzzi, F. Lombardo, A. Amore et al., "Low reninangiotensin system activity gene polymorphism and dysplasia associated with posterior urethral valves," Journal of Urology, vol. 174, no. 2, pp. 713-717, 2005. 
[47] A. Stanković, M. Zivković, M. Kostić et al., "Expression profiling of the AT2R mRNA in affected tissue from children with CAKUT," Clinical Biochemistry, vol. 43, no. 1-2, pp. 71$75,2010$.

[48] S. Weber, J. C. Taylor, P. Winyard et al., "SIX2 and BMP4 mutations associate with anomalous kidney development," Journal of the American Society of Nephrology, vol. 19, no. 5, pp. 891-903, 2008.

[49] K. Suzuki, R. Haraguchi, T. Ogata et al., "Abnormal urethra formation in mouse models of Split-hand/split-foot malformation type 1 and type 4," European Journal of Human Genetics, vol. 16, no. 1, pp. 36-44, 2008.

[50] P. M. A. Groenen, G. Vanderlinden, K. Devriendt, J. P. Fryns, and W. J. M. Van De Ven, "Rearrangement of the human CDC5L gene by a $\mathrm{t}(6 ; 19)(\mathrm{p} 21 ; \mathrm{q} 13.1)$ in a patient with multicystic renal dysplasia," Genomics, vol. 49, no. 2, pp. 218-229, 1998.

[51] S. Abdelhak, V. Kalatzis, R. Heilig et al., "A human homologue of the Drosophila eyes absent gene underlies branchiooto-renal (BOR) syndrome and identifies a novel gene family," Nature Genetics, vol. 15, no. 2, pp. 157-164, 1997.

[52] S. Jadeja, I. Smyth, J. E. Pitera et al., "Identification of a new gene mutated in Fraser syndrome and mouse myelencephalic blebs," Nature Genetics, vol. 37, no. 5, pp. 520-525, 2005.

[53] T. Nakano, F. Niimura, K. Hohenfellner, E. Miyakita, and I. Ichikawa, "Screening for mutations in BMP4 and FOXC1 genes in congenital anomalies of the kidney and urinary tract in humans," Tokai Journal of Experimental and Clinical Medicine, vol. 28, no. 3, pp. 121-126, 2003.

[54] H. Van Esch, P. Groenen, M. A. Nesbit et al., "GATA3 haploinsufficiency causes human HDR syndrome," Nature, vol. 406, no. 6794, pp. 419-422, 2000.

[55] T. Ulinski, S. Lescure, S. Beaufils et al., "Renal phenotypes related to hepatocyte nuclear factor- $1 \beta$ (TCF2) mutations in a pediatric cohort," Journal of the American Society of Nephrology, vol. 17, no. 2, pp. 497-503, 2006.

[56] T. H. Lindner, P. R. Njølstad, Y. Horikawa, L. Bostad, G. I. Bell, and O. Søvik, "A novel syndrome of diabetes mellitus, renal dysfunction and genital malformation associated with a partial deletion of the pseudo-POU domain of hepatocyte nuclear factor-1 $\beta$," Human Molecular Genetics, vol. 8, no. 11, pp. 2001-2008, 1999.

[57] P. Sanyanusin, L. A. Schimmenti, L. A. McNoe et al., "Mutation of the PAX2 gene in a family with optic nerve colobomas, renal anomalies and vesicoureteral reflux," Nature Genetics, vol. 9, no. 4, pp. 358-364, 1995.

[58] J. Martinovic-Bouriel, A. Benachi, M. Bonnière et al., "PAX2 mutations in fetal renal hypodysplasia," American Journal of Medical Genetics, Part A, vol. 152, no. 4, pp. 830-835, 2010.

[59] U. Grieshammer, L. Ma, A. S. Plump, F. Wang, M. TessierLavigne, and G. R. Martin, "SLIT2-mediated ROBO2 signaling restricts kidney induction to a single site," Developmental Cell, vol. 6, no. 5, pp. 709-717, 2004.

[60] A. M. Bertoli-Avella, M. L. Conte, F. Punzo et al., "ROBO2 gene variants are associated with familial vesicoureteral reflux," Journal of the American Society of Nephrology, vol. 19, no. 4, pp. 825-831, 2008.

[61] W. Lu, A. M. Van Eerde, X. Fan et al., "Disruption of ROBO2 is associated with urinary tract anomalies and confers risk of vesicoureteral reflux," The American Journal of Human Genetics, vol. 80, no. 4, pp. 616-632, 2007.

[62] T. C. Hart, M. C. Gorry, P. S. Hart et al., "Mutations of the UMOD gene are responsible for medullary cystic kidney disease 2 and familial juvenile hyperuricaemic nephropathy," Journal of Medical Genetics, vol. 39, no. 12, pp. 882-892, 2002.

[63] E. Benetti, G. Caridi, M. D. Vella et al., "Immature renal structures associated with a novel UMOD sequence variant," American Journal of Kidney Diseases, vol. 53, no. 2, pp. 327331, 2009.

[64] D. Jenkins, M. Bitner-Glindzicz, L. Thomasson et al., "Mutational analyses of UPIIIA, SHH, EFNB2, and HNF1 $\beta$ in persistent cloaca and associated kidney malformations," Journal of Pediatric Urology, vol. 3, no. 1, pp. 2-9, 2007.

[65] P. Hu, F. M. Deng, F. X. Liang et al., "Ablation of uroplakin III gene results in small urothelial plaques, urothelial leakage, and vesicoureteral reflux," Journal of Cell Biology, vol. 151, no. 5, pp. 961-972, 2000.

[66] P. M. A. Groenen, E. Garcia, P. Debeer, K. Devriendt, J. P. Fryns, and W. J. M. Van De Ven, "Structure, sequence, and chromosome 19 localization of human USF2 and its rearrangement in a patient with multicystic renal dysplasia," Genomics, vol. 38, no. 2, pp. 141-148, 1996.

[67] J. F. O’Toole, Y. Liu, E. E. Davis et al., "Individuals with mutations in $\mathrm{XPNPEP}_{3}$, which encodes a mitochondrial protein, develop a nephronophthisis-like nephropathy," Journal of Clinical Investigation, vol. 120, no. 3, pp. 791-802, 2010.

[68] I. V. Yosypiv, "Renin-angiotensin system in ureteric bud branching morphogenesis: insights into the mechanisms," Pediatric Nephrology, vol. 26, no. 9, pp. 1499-1512, 2011.

[69] X. Nie, J. Sun, R. E. Gordon, C. L. Cai, and P. X. Xu, "SIX1 acts synergistically with TBX18 in mediating ureteral smooth muscle formation," Development, vol. 137, no. 5, pp. 755$765,2010$.

[70] M. Marini, F. Giacopelli, M. Seri, and R. Ravazzolo, "Interaction of the LMX1B and PAX2 gene products suggests possible molecular basis of differential phenotypes in Nail-Patella syndrome," European Journal of Human Genetics, vol. 13, no. 6, pp. 789-792, 2005.

[71] P. R. Fain, K. K. McFann, M. R. G. Taylor et al., "Modifier genes play a significant role in the phenotypic expression of PKD1," Kidney International, vol. 67, no. 4, pp. 1256-1267, 2005.

[72] T. Hiesberger, X. Shao, E. Gourley, A. Reimann, M. Pontoglio, and P. Igarashi, "Role of the hepatocyte nuclear factor- $1 \beta$ (HNF-1 $\beta$ ) C-terminal domain in Pkhd1 (ARPKD) gene transcription and renal cystogenesis," The Journal of Biological Chemistry, vol. 280, no. 11, pp. 10578-10586, 2005.

[73] M. A. Garcia-Gonzalez, L. F. Menezes, K. B. Piontek et al., "Genetic interaction studies link autosomal dominant and recessive polycystic kidney disease in a common pathway," Human Molecular Genetics, vol. 16, no. 16, pp. 1940-1950, 2007.

[74] I. Kim, Y. Fu, K. Hui et al., "Fibrocystin/polyductin modulates renal tubular formation by regulating polycystin-2 expression and function," Journal of the American Society of Nephrology, vol. 19, no. 3, pp. 455-468, 2008.

[75] S. R. Patel, D. Kim, I. Levitan, and G. R. Dressler, "The BRCTdomain containing protein PTIP links PAX2 to a histone H3, lysine 4 methyltransferase complex," Developmental Cell, vol. 13, no. 4, pp. 580-592, 2007.

[76] S. J. M. Welham, P. R. Riley, A. Wade, M. Hubank, and A. S. Woolf, "Maternal diet programs embryonic kidney gene expression,” Physiological Genomics, vol. 22, no. 1, pp. 48-56, 2005.

[77] S. Rossetti and P. C. Harris, "Genotype-phenotype correlations in autosomal dominant and autosomal recessive 
polycystic kidney disease," Journal of the American Society of Nephrology, vol. 18, no. 5, pp. 1374-1380, 2007.

[78] M. Chaki, J. Hoefele, S. J. Allen et al., "Genotype-phenotype correlation in 440 patients with NPHP-related ciliopathies," Kidney International, vol. 80, no. 11, pp. 1239-1245, 2011.

[79] E. Denamur, A. L. Delezoide, C. Alberti et al., "Genotypephenotype correlations in fetuses and neonates with autosomal recessive polycystic kidney disease," Kidney International, vol. 77, no. 4, pp. 350-358, 2010.

[80] R. Magistroni, N. He, K. Wang et al., "Genotype-renal function correlation in type 2 autosomal dominant polycystic kidney disease," Journal of the American Society of Nephrology, vol. 14, no. 5, pp. 1164-1174, 2003.

[81] H. S. Lo, Z. Wang, Y. Hu et al., "Allelic variation in gene expression is common in the human genome," Genome Research, vol. 13, no. 8, pp. 1855-1862, 2003.

[82] J. R. Sampson, M. M. Maheshwar, R. Aspinwall et al., "Renal cystic disease in tuberous sclerosis: role of the polycystic kidney disease 1 gene," The American Journal of Human Genetics, vol. 61, no. 4, pp. 843-851, 1997.

[83] J. M. Shillingford, N. S. Murcia, C. H. Larson et al., "The mTOR pathway is regulated by polycystin-1, and its inhibition reverses renal cystogenesis in polycystic kidney disease," Proceedings of the National Academy of Sciences of the United States of America, vol. 103, no. 14, pp. 5466-5471, 2006.

[84] A. Persu, M. Duyme, Y. Pirson et al., "Comparison between siblings and twins supports a role for modifier genes in ADPKD," Kidney International, vol. 66, no. 6, pp. 2132-2136, 2004.

[85] C. J. Mache, K. H. Preisegger, S. Kopp, M. Ratschek, and E. Ring, "De novo HNF-1 $\beta$ gene mutation in familial hypoplastic glomerulocystic kidney disease," Pediatric Nephrology, vol. 17, no. 12, pp. 1021-1026, 2002.

[86] E. L. Edghill, C. Bingham, S. Ellard, and A. T. Hattersley, "Mutations in hepatocyte nuclear factor- $1 \beta$ and their related phenotypes," Journal of Medical Genetics, vol. 43, no. 1, pp. 84-90, 2006.

[87] L. Gresh, E. Fischer, A. Reimann et al., "A transcriptional network in polycystic kidney disease," The EMBO Journal, vol. 23, no. 7, pp. 1657-1668, 2004.

[88] C. Bergmann, J. von Bothmer, N. Ortiz Brüchle et al., "Mutations in multiple PKD genes may explain early and severe polycystic kidney disease," Journal of the American Society of Nephrology, vol. 22, no. 11, pp. 2047-2056, 2011.

[89] K. Tory, T. Lacoste, L. Burglen et al., "High NPHP1 and NPHP6 mutation rate in patients with Joubert syndrome and nephronophthisis: potential epistatic effect of NPHP6 and AHI1 mutations in patients with NPHP1 mutations," Journal of the American Society of Nephrology, vol. 18, no. 5, pp. 15661575, 2007.

[90] C. L. Smith, "A shifting paradigm: histone deacetylases and transcriptional activation," BioEssays, vol. 30, no. 1, pp. 1524, 2008.

[91] A. Nottke, M. P. Colaiácovo, and Y. Shi, "Developmental roles of the histone lysine demethylases," Development, vol. 136, no. 6, pp. 879-889, 2009.

[92] K. Surendran and R. Kopan, "Chromatin-based mechanisms of renal epithelial differentiation," Journal of the American Society of Nephrology, vol. 22, no. 7, pp. 1208-1212, 2011.

[93] S. Chen, C. Bellew, X. Yao et al., "Histone deacetylase (HDAC) activity is critical for embryonic kidney gene expression, growth, and differentiation," The Journal of Biological Chemistry, vol. 286, no. 37, pp. 32775-32789, 2011.
[94] M. K. Skinner, "Environmental epigenetic transgenerational inheritance and somatic epigenetic mitotic stability," Epigenetics, vol. 6, no. 7, pp. 838-842, 2011.

[95] E. McPherson, J. Carey, A. Kramer et al., "Dominantly inherited renal adysplasia," American Journal of Medical Genetics, vol. 26, no. 4, pp. 863-872, 1987.

[96] S. K. Chan, P. R. Riley, K. L. Price et al., "Corticosteroidinduced kidney dysmorphogenesis is associated with deregulated expression of known cystogenic molecules, as well as Indian hedgehog," American Journal of Physiology, vol. 298, no. 2, pp. F346-F356, 2010.

[97] L. L. Woods, J. R. Ingelfinger, J. R. Nyengaard, and R. Rasch, "Maternal protein restriction suppresses the newborn reninangiotensin system and programs adult hypertension in rats," Pediatric Research, vol. 49, no. 4, pp. 460-467, 2001.

[98] N. Koleganova, G. Piecha, E. Ritz et al., "Both high and low maternal salt intake in pregnancy alter kidney development in the offspring," American Journal of Physiology, vol. 301, no. 2, pp. F344-F354, 2011.

[99] M. Battin, S. Albersheim, and D. Newman, "Congenital genitourinary tract abnormalities following cocaine exposure in utero," American Journal of Perinatology, vol. 12, no. 6, pp. 425-428, 1995.

[100] Q. Qazi, A. Masakawa, D. Milman et al., "Renal anomalies in fetal alcohol syndrome," Pediatrics, vol. 63, no. 6, pp. 886889, 1979.

[101] S. S. El-Dahr, L. M. Harrison-Bernard, S. Dipp, I. V. Yosipiv, and S. Meleg-Smith, "Bradykinin B2 null mice are prone to renal dysplasia: gene-environment interactions in kidney development," Physiological Genomics, vol. 3, no. 3, pp. 121131, 2000.

[102] M. F. Schreuder, R. R. Bueters, M. C. Huigen, F. G. M. Russel, R. Masereeuw, and L. P. Van Den Heuvel, "Effect of drugs on renal development," Clinical Journal of the American Society of Nephrology, vol. 6, no. 1, pp. 212-217, 2011.

[103] A. Köttgen, "Genome-wide association studies in nephrology research," American Journal of Kidney Diseases, vol. 56, no. 4, pp. 743-758, 2010.

[104] D. N. Cooper, M. Krawchak, and S .E. Antonorakis, "The nature and mechanisms of human gene mutation," in The Metabolic and Molecular Bases of Inherited Diseases, Charles R. Scriver, W. S. Beaudet, and D. Valle, Eds., pp. 259-291, McGraw-Hill, New York, NY, USA, 7th edition, 1995.

[105] M. J. Bamshad, S. B. Ng, A. W. Bigham et al., "Exome sequencing as a tool for Mendelian disease gene discovery," Nature Reviews Genetics, vol. 12, no. 11, pp. 745-755, 2011. 


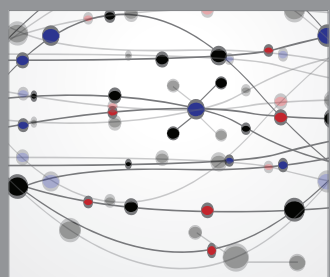

The Scientific World Journal
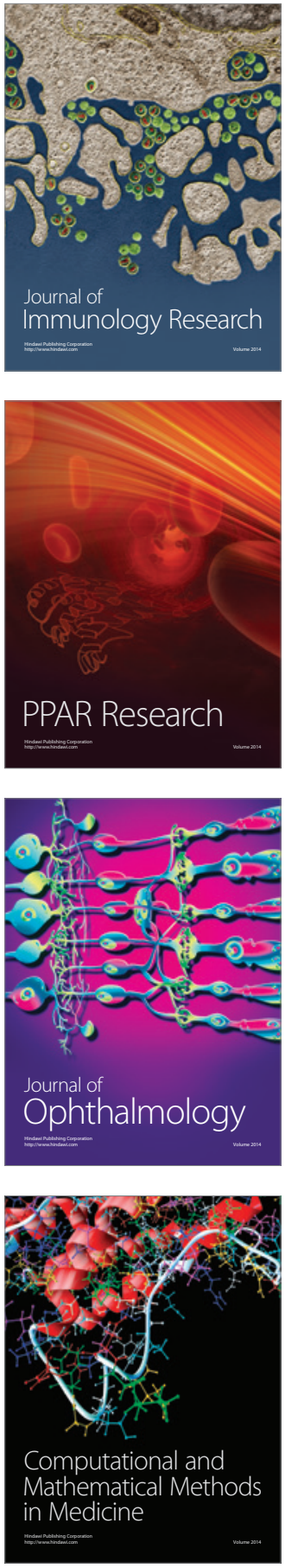

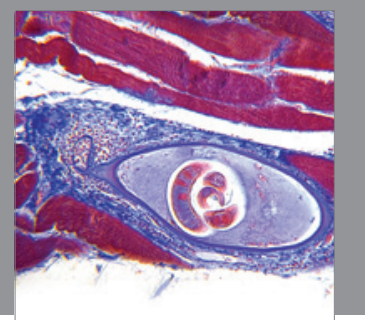

Gastroenterology

Research and Practice
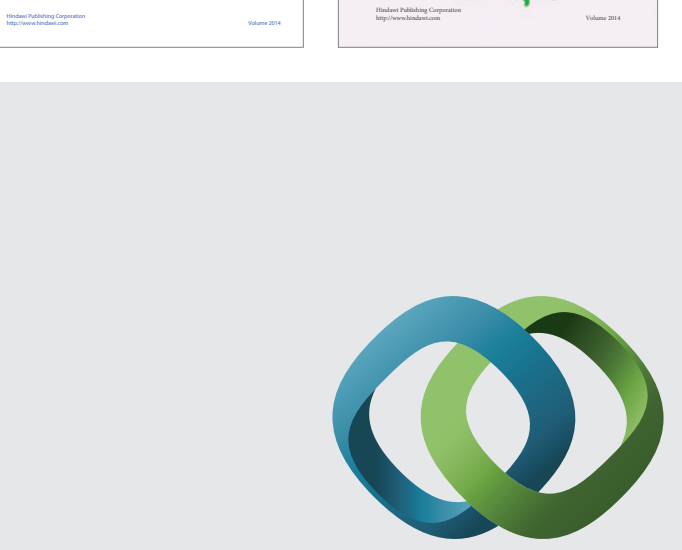

\section{Hindawi}

Submit your manuscripts at

http://www.hindawi.com
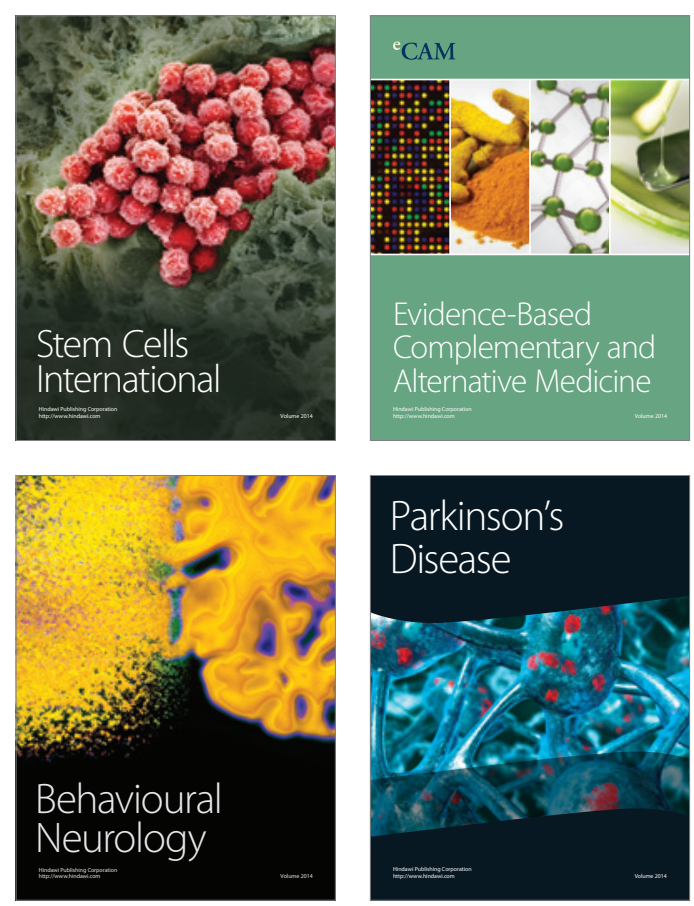

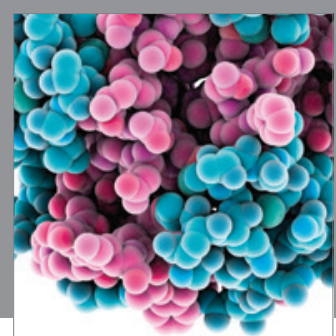

Journal of
Diabetes Research

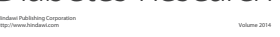

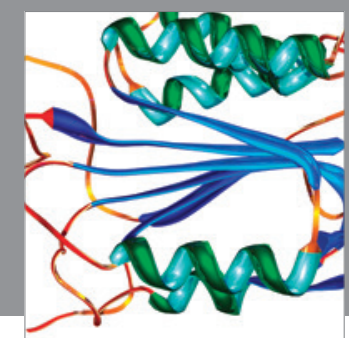

Disease Markers
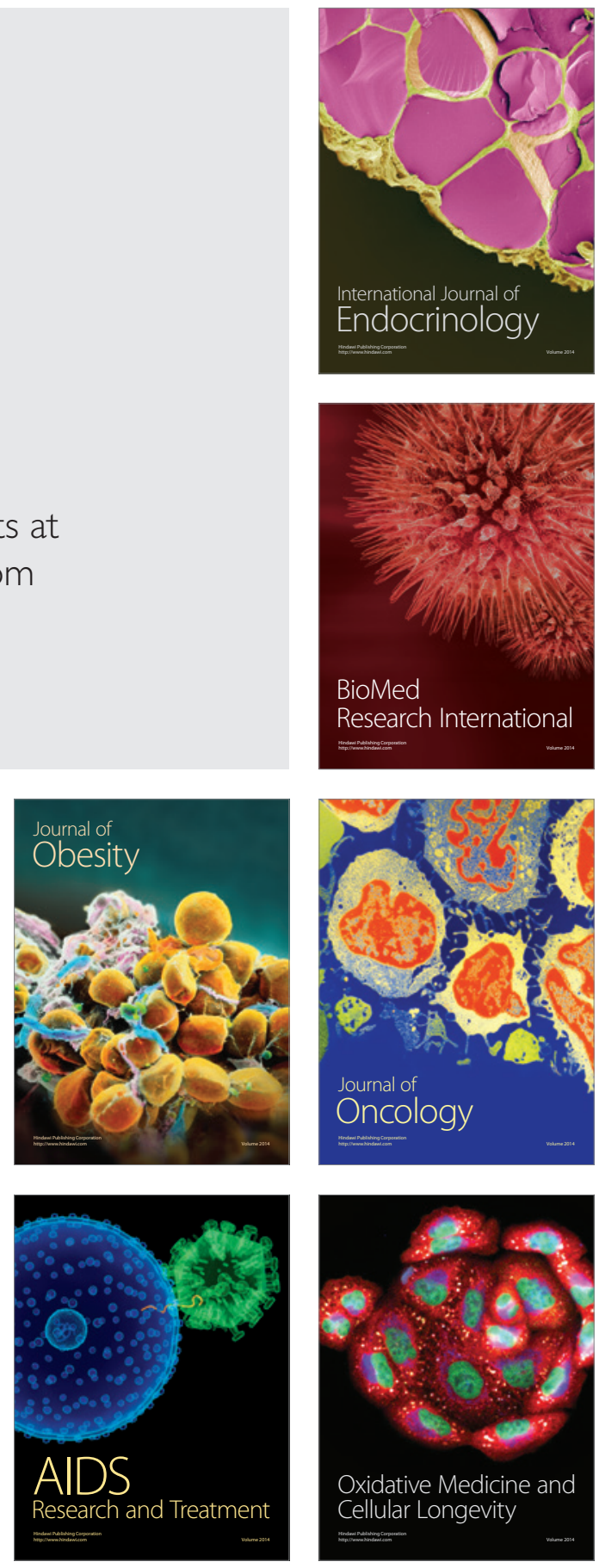